\title{
Article \\ Temperature Responsive Polymer Conjugate Prepared by "Grafting from" Proteins toward the Adsorption and Removal of Uremic Toxin
}

\author{
Erika Yoshihara $^{1,2}$, Makoto Sasaki ${ }^{1,2} \mathbb{D}$, Ahmed Nabil ${ }^{1,3,4} \mathbb{D}$, Michihiro Iijima $^{5}\left(\mathbb{D}\right.$ and Mitsuhiro Ebara and $^{1,2, *}(\mathbb{D}$ \\ 1 Research Center for Functional Materials (RCFM), National Institute for Materials Science (NIMS), \\ 1-1 Namiki, Tsukuba 305-0044, Japan; erika.0530.y@gmail.com (E.Y.); s2020340@s.tsukuba.ac.jp (M.S.); \\ DRNABIL_100@hotmail.com (A.N.) \\ 2 Graduate School of Pure and Applied Sciences, University of Tsukuba, 1-1-1 Tennodai, \\ Tsukuba 305-8577, Japan \\ 3 Biotechnology and Life Sciences Department, Faculty of Postgraduate Studies for Advanced Sciences (PSAS), \\ Beni-Suef University, Beni-Suef 62511, Egypt \\ 4 Egyptian Liver Research Institute and Hospital (ELRIAH), El Mansoura, 35511, Egypt \\ 5 Department of Materials Chemistry and Bioengineering, National Institute of Technology, Oyama \\ College (NIT, Oyama College), 771 Nakakuki, Oyama 323-0806, Japan; iijima@oyama-ct.ac.jp \\ 6 Graduate School of Industrial Science and Technology, Tokyo University of Science, 1-3 Kagurazaka, \\ Shinjuku, Tokyo 162-0825, Japan \\ * Correspondence: EBARA.Mitsuhiro@nims.go.jp
}

check for updates

Citation: Yoshihara, E.; Sasaki, M.; Nabil, A.; Iijima, M.; Ebara, M. Temperature Responsive Polymer Conjugate Prepared by "Grafting from" Proteins toward the Adsorption and Removal of Uremic Toxin. Molecules 2022, 27, 1051. https://doi.org/10.3390/ molecules27031051

Academic Editors: Grégorio Crini, Ana Rita Lado Ribeiro, Corina Bradu, Lorenzo Antonio Picos Corrales and Lee D. Wilson

Received: 7 January 2022

Accepted: 1 February 2022

Published: 3 February 2022

Publisher's Note: MDPI stays neutral with regard to jurisdictional claims in published maps and institutional affiliations.

Copyright: (C) 2022 by the authors. Licensee MDPI, Basel, Switzerland. This article is an open access article distributed under the terms and conditions of the Creative Commons Attribution (CC BY) license (https:// creativecommons.org/licenses/by/ $4.0 /)$.

\begin{abstract}
In this study, temperature-responsive polymer-protein conjugate was synthesized using a "grafting from" concept by introducing a chain transfer agent (CTA) into bovine serum albumin (BSA). The BSA-CTA was used as a starting point for poly(N-isopropylacrylamide) (PNIPAAm) through reversible addition-fragmentation chain transfer polymerization. The research investigations suggest that the thermally responsive behavior of PNIPAAm was controlled by the monomer ratio to CTA, as well as the amount of CTA introduced to BSA. The study further synthesized the human serum albumin (HSA)-PNIPAAm conjugate, taking the advantage that HSA can specifically adsorb indoxyl sulfate (IS) as a uremic toxin. The HSA-PNIPAAm conjugate could capture IS and decreased the concentration by about $40 \%$ by thermal precipitation. It was also revealed that the protein activity was not impaired by the conjugation with PNIPAAm. The proposed strategy is promising in not only removal of uremic toxins but also enrichment of biomarkers for early diagnostic applications.
\end{abstract}

Keywords: polymer-protein conjugates; poly(N-Isopropylacrylamide); serum albumin; grafting from; indoxyl sulfate

\section{Introduction}

Polymer-protein conjugates (PPCs) have been extensively developed in the last decades both in academic and industrial areas. The synthesis of bioconjugate materials mainly utilizes natural amino acids that exist within protein and peptide structures. Introduction of polymers into protein makes it possible for new functionalities such as improving solubility, enhancing dispersibility and inhibiting proteolytic enzymes. Such approaches are known to have promising applications as therapeutic and/or diagnostic technologies [1]. Generally, there are two common strategies for introducing polymers into proteins in PPCs: "Grafting to" (GT) approach bonds pre-synthesized polymers to proteins with functional groups by reactive coupling. "Grafting from" (GF) approach, on the other hand, initiates site for polymerization in aqueous solution through functionalized protein [2].

Poly ( $N$-isopropylacrylamide) (PNIPAAm) is one of the most extensively studied temperature-responsive polymers in PPCs, which has a lower critical solution temperature (LCST) of around $32{ }^{\circ} \mathrm{C}$ [3]. Based on this property, protein-PNIPAAm conjugates can 
possess a temperature-sensitive ON-OFF switching functionality and can be used for protein recovery by thermal precipitation around body temperature [4]. Mainly, the GT approach is used for the protein-PNIPAAm conjugates because of its high coupling reaction efficiency and variable reaction conditions. Hoffman et al. have successfully prepared conjugates with a series of amine-containing proteins including lysozyme, myoglobin, protein A, hemoglobin, albumin and $\gamma$-globulin by using NIPAAm copolymer with $N$ hydroxysuccinimide (NHS) [5,6]. They have also succeeded in simplifying the structure of protein-polymer conjugates by implementing radical polymerization of NIPAAm from the polymerization initiation site with a carbonyl group at the polymer ends, which allowed the protein to bind a single end attachment to the polymer chain [7-9]. Okano et al. have also synthesized semitelechelic PNIPAAm with NHS groups at the polymer ends and successfully conjugated it with antibodies $[10,11]$. The conjugation of primary amino group and activated esters has been also used to prepare responsive macromolecular bioconjugates through streptavidin rather than direct conjugation onto the target protein [12-18]. In addition, it has been recently reported the preparation of conjugates under biological conditions and the introduction of functional groups into proteins by modifying PNIPAAmderived copolymers by click reactions [19-23]. However, these methods involve complex processes such as multistep synthesis of PNIPAAm-derived polymers, functionalization of the polymer end groups and associated purification. In addition, introducing polymers to protein is inefficient due to steric hindrance. To improve efficiency, there is need to add excess polymers, which is challenging due to lack of control to the numbers and positions of PNIPAAm introduced in the protein surface.

To overcome these drawbacks, GF approach has attracted considerable attention in recent years due to its one-step preparation procedure and simple purification. GF approach uses functionalized proteins as initiation sites from where monomers are polymerized through living radical polymerization in an aqueous solution. However, only few reports have investigated the introduction of PNIPAAm into proteins through reversible additionfragmentation chain transfer (RAFT) polymerization [24-28]. These reports confirmed the successful living radical polymerization of NIPAAm from proteins and the retained activity of protein-polymer conjugates after PNIPAAm introduction. Other reports mention the conjugation of protein-PNIPAAm prepared through atom transfer radical polymerization (ATRP). However, the removal of copper catalyst as well as deoxidization of solvent have been big challenges for the biological applications [29].

This study aims to prepare protein-PNIPAAm conjugates with the GF approach by functionalizing bovine serum albumin (BSA) with chain transfer agent (CTA) groups as an initiation site for the polymerization of NIPAAm (Scheme 1). Serum albumin was selected not only as a model protein, but also its adsorption ability for uremic toxin. The RAFT agent with NHS group (NHS-CTA) was used to react with the BSA amino group to synthesize macro-CTA. Moreover, in thermal RAFT polymerization, free linear polymers can be synthesized at the same time as the introduction of PNIPAAm into proteins and we believe that this will improve work efficiency because there is no need to add free PNIPAAm later to improve thermal precipitation efficiency. The study specifically investigated the synthetic conditions based on monomer ratio and amount of introduced CTA because increasing the thermal precipitation efficiency of conjugates improves the recovery of conjugated protein, allowing for a broader range of future applications across various fields. Finally, this study tried to demonstrate the adsorption and removal of uremic toxin, indoxyl sulfate (IS) using human serum albumin (HSA)-PNIPAAm conjugate (Figure 1). 


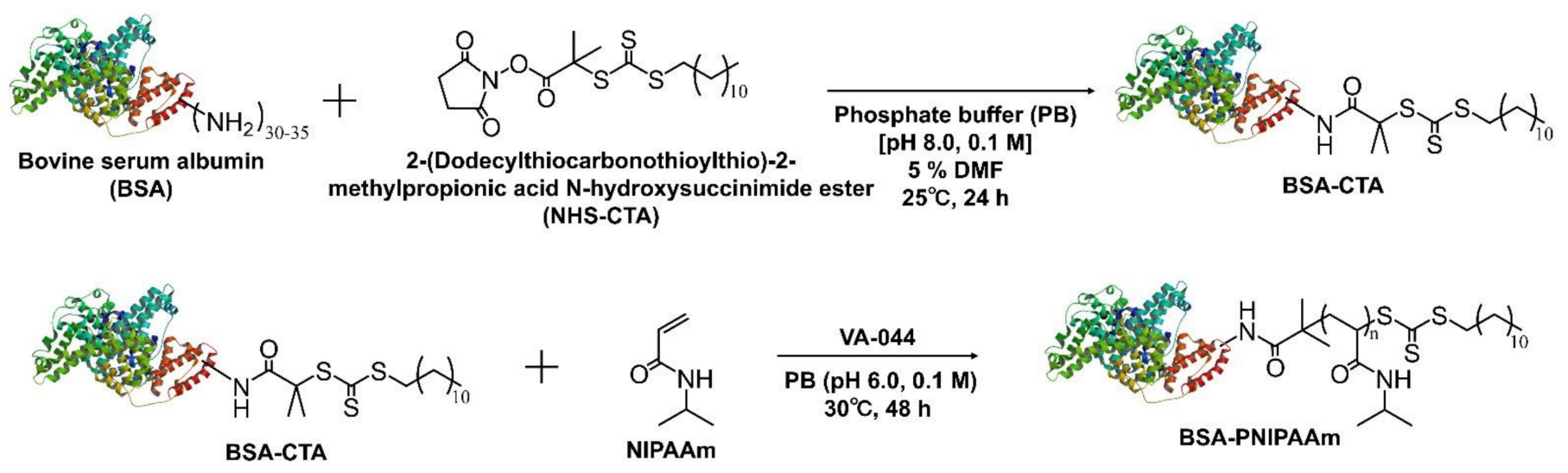

Scheme 1. Synthesis of BSA-PNIPAAm conjugate by RAFT polymerization.

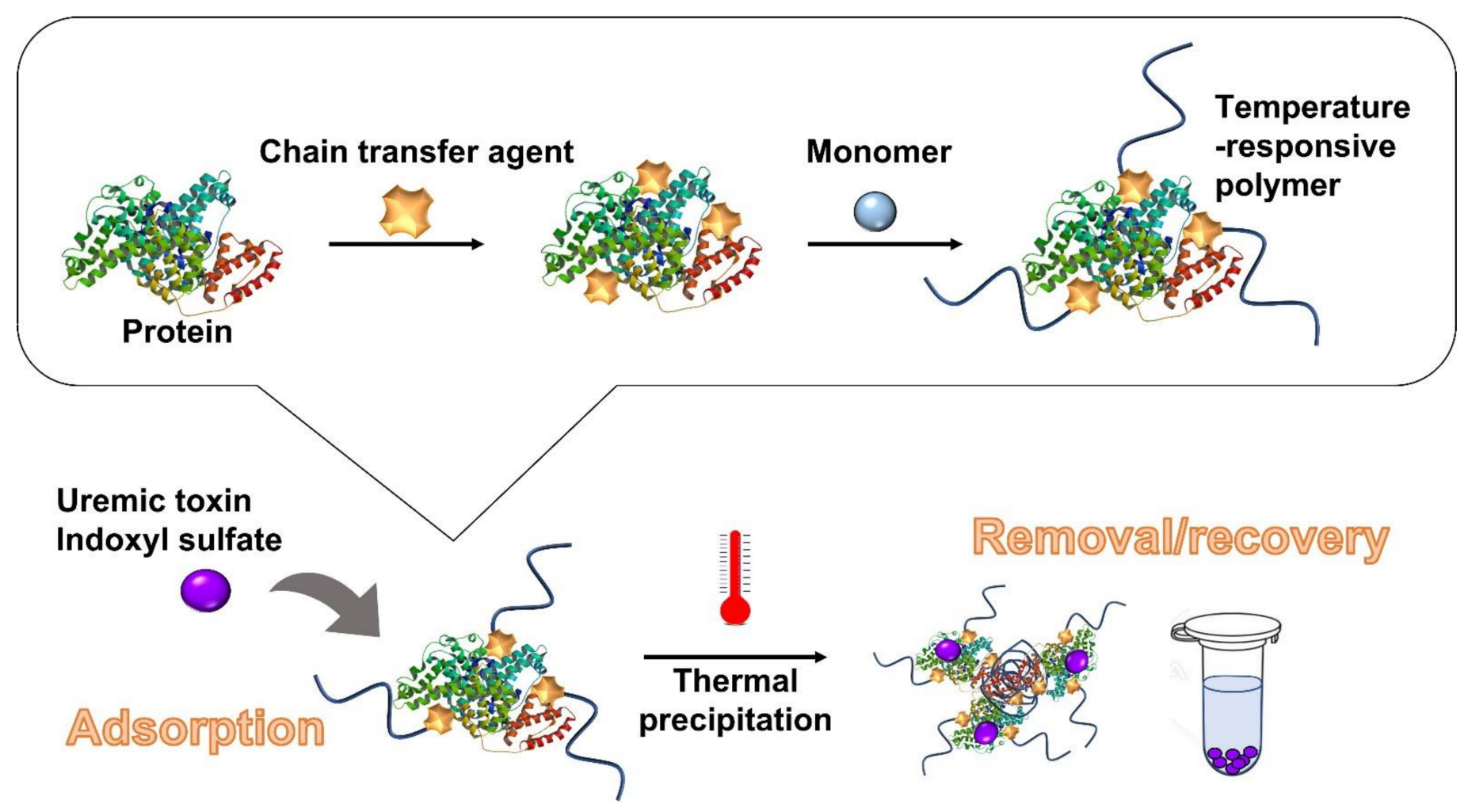

Figure 1. Schematic of the proposed thermally responsive polymer-protein conjugate system. First, protein-PNIPAAm was prepared by "grafting from" method. Next, the conjugate is allowed to capture indoxyl sulfate (IS), one of the uremic toxins. Finally, the captured IS is recovered by thermal precipitation.

\section{Results and Discussion}

\subsection{Synthesis of BSA-CTA}

First, conjugation of the CTA to BSA was confirmed by UV spectroscopy. Figure 2 (left) shows the absorbance of BSA-CTA at $310 \mathrm{~nm}$ which is derived from thiocarbonyl groups (Figure S1). The higher the NHS-CTA ratio, the higher its absorbance. The peak reached a plateau at 5 mole equivalents against BSA. This result is in a good agreement with previous reports that used NHS-CTA for reaction with protein amino groups [24]. The successful conjugation was also confirmed by observing unreacted amino residues in the BSA. The unreacted amino residues were labeled with fluorescamine and its fluorescence intensity was observed. The results that are shown in Figure 2 (right) indicate that by increasing the amount of NHS-CTA, the fluorescence intensity of fluorescamine at $495 \mathrm{~nm}$ increased, 
which indicates that bare amino residues decreased. The intensity reached a plateau around 5-10 mole equivalent against BSA. This shows a quantitative relationship between the introduced CTA group and modified amino residue, suggesting that the amount of CTA introduced can be controlled by feeding ratio of NHS-CTA. Table 1 summarizes the feeding ratios and the obtained intensities.

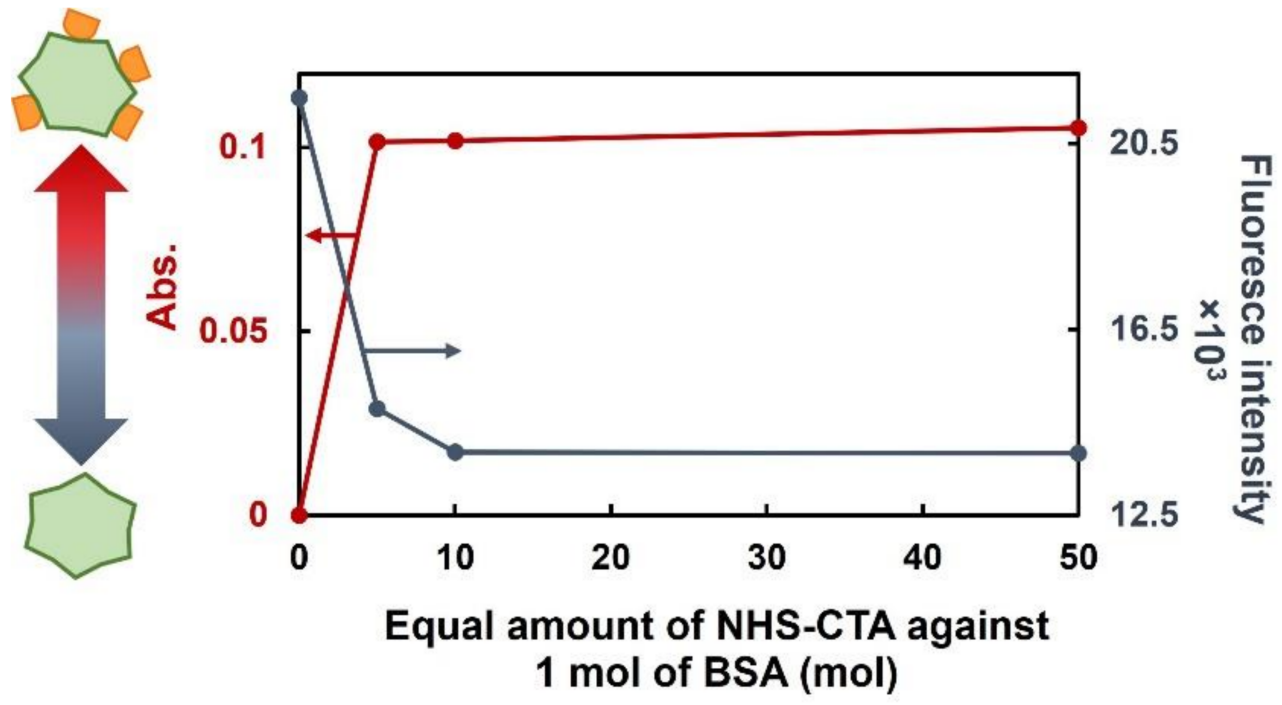

Figure 2. (Left) UV absorbance of BSA-CTA with different feeding ratios at $310 \mathrm{~nm}$. The absorbance intensity was calculated by comparing thiocarbonyl group of CTA $(310 \mathrm{~nm})$ to BSA $(280 \mathrm{~nm})(\mathrm{red})$. (Right) Fluorescence intensity of fluorescamine at $495 \mathrm{~nm}$ conjugated with unreacted amino residues in BSA-CTA (blue).

Table 1. Feeding ratios of BSA-CTA.

\begin{tabular}{|c|c|c|c|c|}
\hline Sample Name & BSA $(\mu \mathrm{mol})$ & $\begin{array}{l}\text { NHS-CTA } \\
\quad(\mu \mathrm{mol})\end{array}$ & $\begin{array}{c}\text { Abs. } \\
(310 \mathrm{~nm} / 280 \mathrm{~nm})\end{array}$ & $\begin{array}{c}\text { Fluorescence } \\
\text { Intensity } \\
\times 10^{3}(495 \mathrm{~nm}) * *\end{array}$ \\
\hline BSA-CTA 0 & 1 & 0 & 0 & 21.5 \\
\hline BSA-CTA 5 & 1 & 5 & 0.1014 & 14.8 \\
\hline BSA-CTA 10 & 1 & 10 & 0.1017 & 13.9 \\
\hline BSA-CTA 50 & 1 & 50 & 0.1052 & 13.8 \\
\hline
\end{tabular}

* The absorbance intensity derived from thiocarbonyl group $(310 \mathrm{~nm})$ against absorbance derived from protein $(280 \mathrm{~nm}) .{ }^{* *}$ The fluorescence intensity derived from fluorescamine $(495 \mathrm{~nm})$ conjugated to unreacted amino residues.

\subsection{Synthesis of BSA-PNIPAAm Conjugates}

First, the model reaction between CTA and monomer only was carried out in PB and the results showed that the molecular weight distribution was narrower than that of free radical polymerization, indicating that the polymerization could be controlled (Figure S2). Next, the preparation conditions for BSA-PNIPAAm conjugates were optimized by changing monomer concentrations (Figure S3). The successful conjugation was confirmed from SDS-PAGE results by comparing the molecular weight bands. The conjugates prepared with $800 \mathrm{mM}$ showed a band broadening compared to $400 \mathrm{mM}$, indicating an increase in the molecular weight (Figures S3 and S4). These findings were in parallel with our previous studies that approved the successful polymeric antibody conjugation [22,23]. Moreover, from ${ }^{1} \mathrm{H}$ NMR, the change in monomer conversion over time confirmed $100 \%$ conversion $48 \mathrm{~h}$ after the reaction (Figure S5). Based on these results, the monomer concentration was set at $800 \mathrm{mM}$ and the reaction time at $48 \mathrm{~h}$ before the subsequent reaction conditions were decided. Under these conditions, various BSA-PNIPAAm conjugates with different monomer ratios and CTA groups were prepared to investigate the effect of polymer chain 
length and the number of polymers by comparing the monomer ratio and the amount of CTA, respectively (Table 2 ).

Table 2. Feeding ratios of BSA-PNIPAAm.

\begin{tabular}{ccc}
\hline \multirow{2}{*}{ Sample Name } & \multicolumn{2}{c}{ Molar Ratio } \\
\cline { 2 - 3 } & CTA/BSA & Monomer/CTA \\
\hline BSA-CTA5-PNIPAAm400 (B/C5/PN400) & 5 & 400 \\
BSA-CTA5-PNIPAAm800 (B/C5/PN800) & 5 & 800 \\
BSA-CTA5-PNIPAAm1600 (B/C5/PN1600) & 5 & 1600 \\
BSA-CTA2-PNIPAAm800 (B/C2/PN800) & 2 & 800 \\
BSA-CTA10-PNIPAAm800 (B/C10/PN800) & 10 & 800 \\
HSA-CTA5-PNIPAAm800 (H/C5/PN800) & 5 & 800 \\
\hline
\end{tabular}

The SDS-PAGE bands in Figure 3a compare samples with different monomer ratios. The band of native BSA was confirmed around $66 \mathrm{kDa}$. The higher monomer ratio had shown band broadening at the higher end of molecular weight spectrum more than $66 \mathrm{kDa}$. This result suggests that an increase in the molecular weight of the conjugates was caused by the increase in the monomer ratio. In contrast, measurement results shown in Figure $3 b$ confirm the band for unreacted BSA becomes thinner with increase in the amount of CTA introduced. This result suggests that CTA introduction amount is directly contributed to improve polymer introduction efficiency. These results were in good agreement with previous papers that characterized and identified a wide range of bands in BSA-PNIPAAm conjugates [24,27].

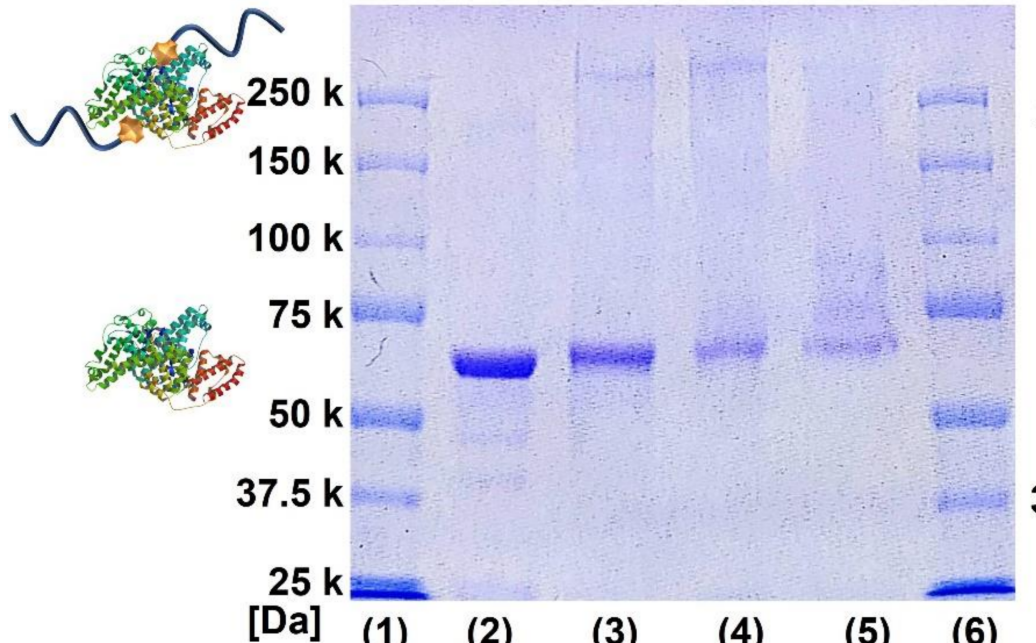

[Da] (1)
(2)
(3) (a)

(4) (5) (6)

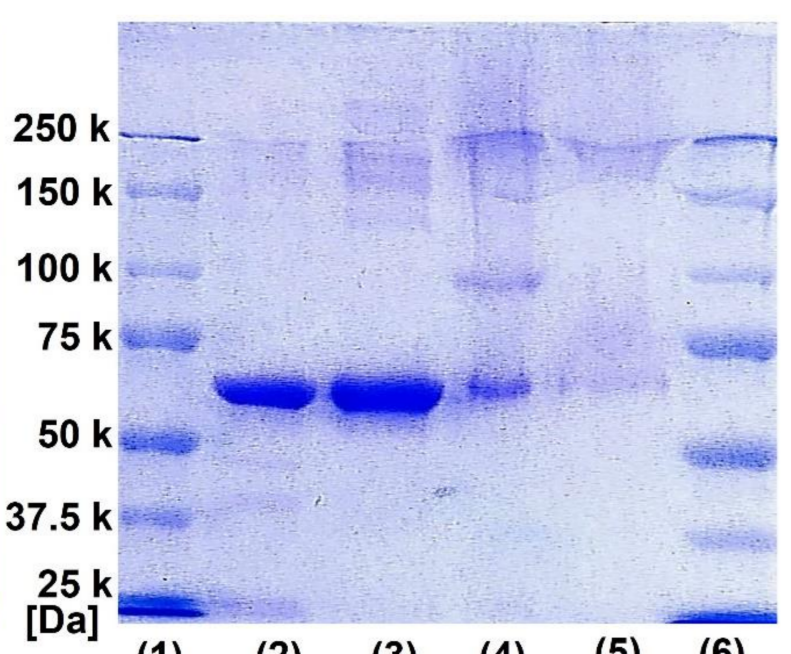

(1)
(2)
(3)

(b)

Figure 3. SDS-PAGE analysis for BSA-PNIPAAm conjugates: (a) Monomer ratio to CTA of BSAPNIPAAm conjugates (lanes: (1) protein standard (2) BSA (3) B/C5/PN400 (4) B/C5/PN800 (5) B/C5/PN1600 (6) protein standard). (b) CTA ratio to BSA of BSA-PNIPAAm conjugates (lanes: (1) protein standard (2) BSA (3) B/C2/PN800 (4) B/C5/PN800 (5) B/C10/PN800 (6) protein standard).

\subsection{Thempretaure-Responsive Phase Transition Behavior}

The temperature-responsive phase transition before and after the conjugation was observed by measuring the LCSTs. LCST was defined as the temperature at which 50\% transmittance was observed. The LCST of the conjugate was observed around $31.0{ }^{\circ} \mathrm{C}$, confirming that the prepared conjugates are temperature responsive (Figure $4 \mathrm{a}$ ). In general, LCST shifts when PNIPAAm is conjugated to proteins by GT method due to the introduced functional group (binding site) in the polymer side or end chain. Indeed, 
the LCST of antibody-PNIPAAm conjugates prepared by GT method was $37^{\circ} \mathrm{C}$ in our previous study [22,23]. Therefore, it may be one of the advantages for GF method that homo NIPAAm can be polymerized from proteins without any comonomers. It may be also plausible that unconjugated PNIPAAm in the solution can affect the phase transition. Therefore, we have also conducted the solution behavior by dynamic light scattering in the following section.

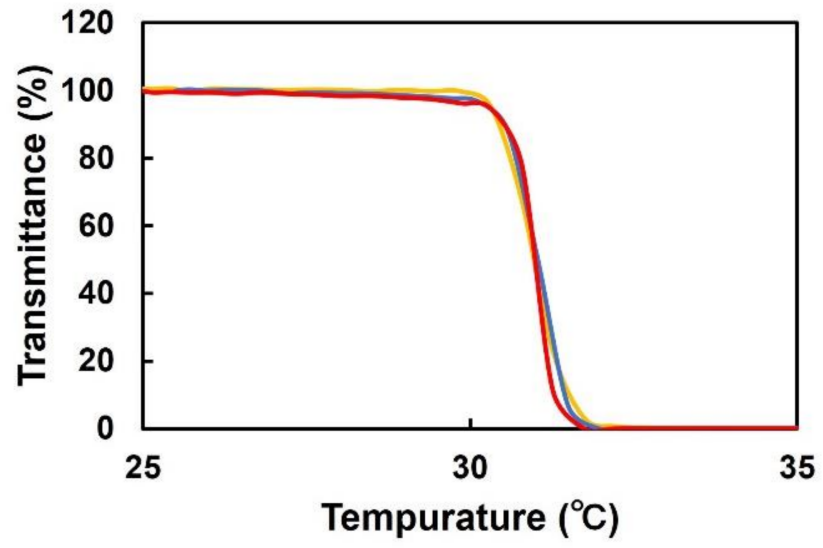

(a)

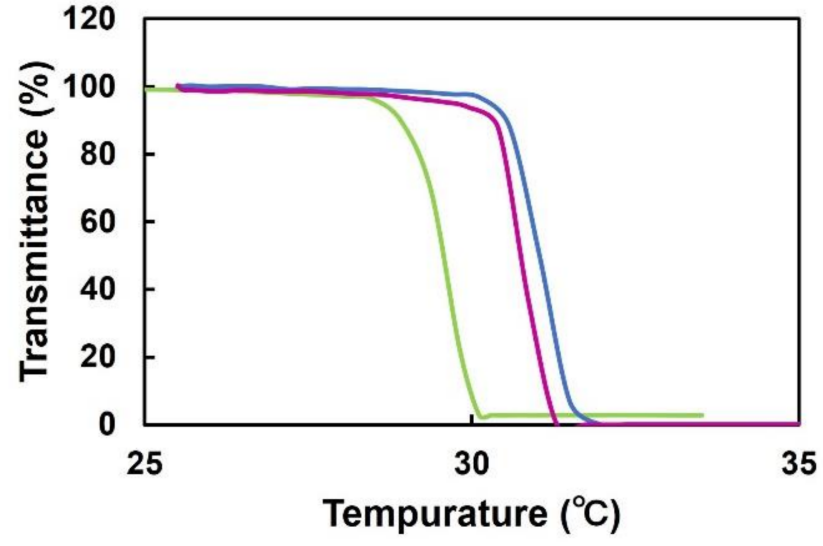

(b)

Figure 4. Transmittance of the BSA-PNIPAAm solutions against temperature (thermal-response): (a) Monomer ratio to CTA. B/C5/PN400 (yellow), B/C5/PN800 (blue), B/C5/PN1600 (red). (b) CTA ratio to BSA. B/C2/PN800 (green), B/C5/PN800 (blue), B/C10/PN800 (purple). (solvent: PBS (pH: 7.4), BSA concentration: $1.0 \mathrm{mg} / \mathrm{mL}$, heating rate: $1^{\circ} \mathrm{C} / \mathrm{min}$, wavelength: $450 \mathrm{~nm}$ ).

\subsection{Temprature-Responsive Aggregation Behavior}

To investigate the dispersibility and temperature-responsive aggregation behavior for the conjugates, DLS measurement was conducted at $35^{\circ} \mathrm{C}$ (above the LCST) (Table 3). The DLS results shown in Figure 5 a confirm the formation of a few hundred nm polymer particles in the samples with monomer ratios of 400 and $800 \mathrm{~mol} \%$. The formation of polymer particles is caused by the phase transition of PNIPAAm, forming the hydrophobic core surrounded by BSA shell. Other literatures also suggested that protein-PNIPAAm conjugates form stable aggregates above the LCST [14,20,28,30,31]. Of particular interest is that the conjugates with less than 2-mole equivalents of CTA did not form the aggregate plausibly due to the insufficient amount of introduced PNIPAAm. On the other hand, the conjugates with 10-mole equivalents amount of CTA did not form stable, monodisperse aggregate [20]. These results indicate that control of CTA introduction directly affects the phase transition behavior of BSA-PNIPAAm conjugates.

Table 3. DLS results of each sample.

\begin{tabular}{ccc}
\hline Sample Name & Size $(\mathbf{n m})$ & PdI \\
\hline BSA-CTA5-PNIPAAm400 (B/C5/PN400) & 170 & 0.04 \\
BSA-CTA5-PNIPAAm800 (B/C5/PN800) & 250 & 0.20 \\
BSA-CTA5-PNIPAAm1600 (B/C5/PN1600) & 1280 & 0.04 \\
BSA-CTA2-PNIPAAm800 (B/C2/PN800) & 3000 & 0.13 \\
BSA-CTA10-PNIPAAm800 (B/C10/PN800) & 920 & 0.19 \\
\hline
\end{tabular}




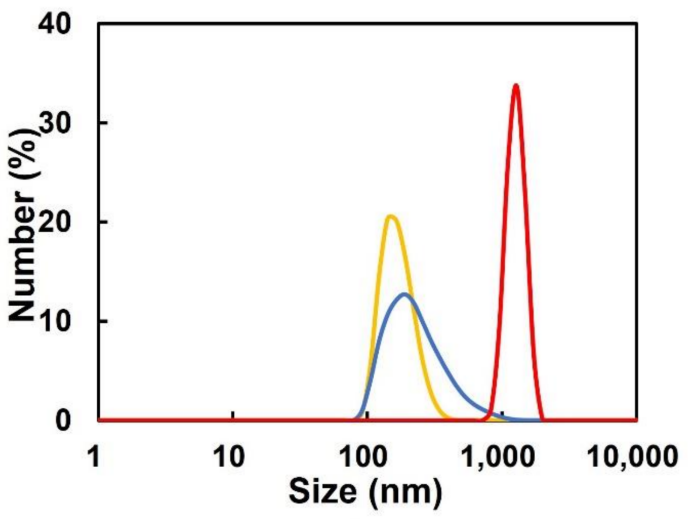

(a)

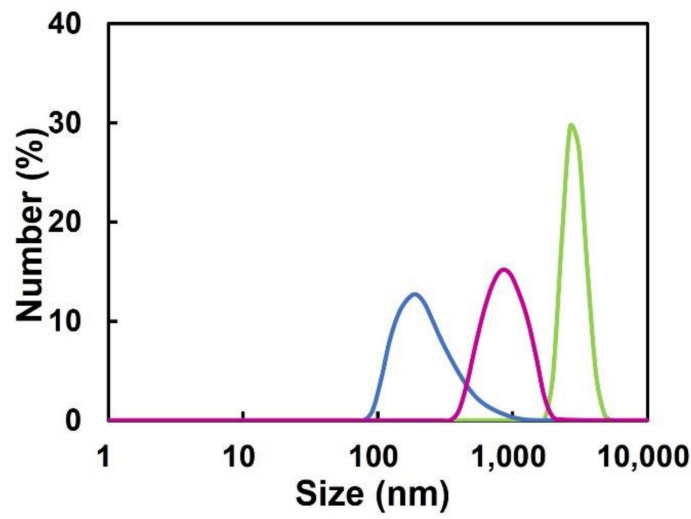

(b)

Figure 5. Confirmation of particle size of BSA-PNIPAAm conjugates by DLS at $35^{\circ} \mathrm{C}$. (a) Monomer ratio to CTA. B/C5/PN400 (yellow), B/C5/PN800 (blue), B/C5/PN1600 (red). (b) CTA ratio to BSA. B/C2/PN800 (green), B/C5/PN800 (blue), B/C10/PN800 (purple).

\subsection{Thermal Precipitation and Recovery of BSA-PNIPAAm}

Figure 6a depicts the thermal precipitation protocol of BSA-PNIPAAm. The BSAPNIPAAm recovery ratio was calculated from the precipitated BSA after thermal precipitation. About $20 \%$ of BSA-PNIPAAm was recovered for the samples with a monomer ratio of 400-mole, while $70 \%$ was recovered when 800 and 1600-mole equivalents samples were used (Figure 6b). From this calculation, no difference was observed between the sample with 800 and 1600-mole equivalents even though the 1600 sample should have higher molecular weight and thus precipitate more. This may be caused by weight loss of the sample during precipitation and re-suspending process. In addition, unconjugated free PNIPAAm may affect bicinchoninic acid (BCA) assay. Therefore, to minimize the error, the recovery ratio was also calculated from a balance between the original solution and supernatant solution as shown in Figure 6a. From this calculation, about $80 \%$ of BSA-PNIPAAm was recovered when the monomer ratio was 1600-mole equivalents. These results suggest that feeding monomer ratio (that is, the molecular weight of PNIPAAm) influences thermal precipitation efficiency. Indeed, the recovery ratio for the samples with a monomer ratio of 400-mole increased to $60 \%$ when free PNIPAAm was added $(400+\mathrm{PN})$.

Figure $6 \mathrm{c}$ shows the effects of CTA on the recovery of BSA-PNIPAAm. The recovery ratios were about $20 \%, 70 \%$ and $80 \%$ for the sample with CTA of 2 mole, 5 mole and 10 mole, respectively. Because amount of introduced CTA directly affects the number of polymer chains on BSA, the sample with higher CTA concentration resulted a higher recovery ratio. The obtained recovery ratio was higher than the ones in previously reported systems using the GT method [22,23].

\subsection{Evaluation of Indoxyl Sulfate (IS) Adsorption Capacity}

Finally, we have examined the adsorption and removal ability of our conjugates toward indoxyl sulfate (IS). IS is one of the uremic toxins that cannot be easily removed via hemodialysis. IS has been also known as a protein-bound molecules, especially human serum albumin (HSA) [32]. Therefore, we have newly designed HSA-PNIPAAm conjugates (H/C5/PN800 in Table 2). First, the IS adsorption isotherms of HSA and HSA-PNIPAAm were prepared (Figure S6). The results showed that HSA conjugated with PNIPAAm had the same IS adsorption capacity as average HSA. Next, thermal precipitation was carried out after the IS adsorption and the concentration of IS in the supernatant was measured, as shown in Figure 7. The HSA-PNIPAAm conjugates reduced the IS concentration by about $40 \%$ compared to the other conditions, indicating the possibility of IS removal by simple thermal precipitation. These results also suggest that PNIPAAm can be introduced into albumin without impairing its activity. Previously, the combination of polymers 
and adsorbents to remove urinary toxins by different methods have been investigated and reported $[33,34]$. In the current approach, the HSA-PNIPAAm conjugates showed IS adsorption ability that is expected to be applied to chronic kidney disease (CKD) and cardiovascular disease (CVD) treatment $[35,36]$. In particular, in the molecular adsorbent recirculating system (MARS) which uses albumin dialysis, if albumin can be simply recovered from the dialysate, it will reduce medical costs. In addition, the introduction of PNIPAAm into proteins other than BSA (e.g., antibodies) using the same technique will enable the creation of conjugates more quickly than the conventional method. This will facilitate the development of different medical approaches, including diagnostics.

(a)

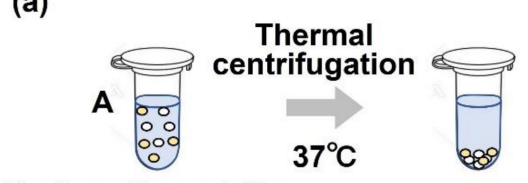

Post-reaction solution

\&: BSA-PNIPAAm \&8: Free PNIPAAm

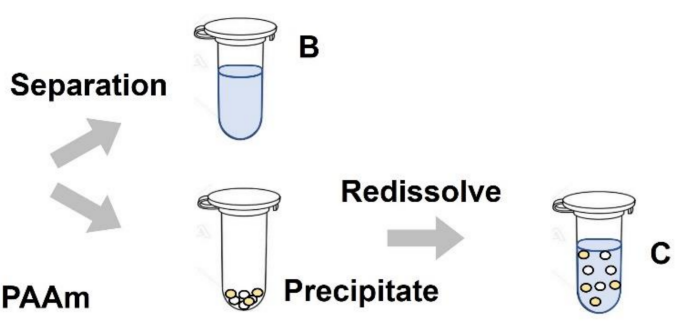

From precipitation

BSA recovery ratio $(\%)=\frac{C}{A} \times 100$

(b)

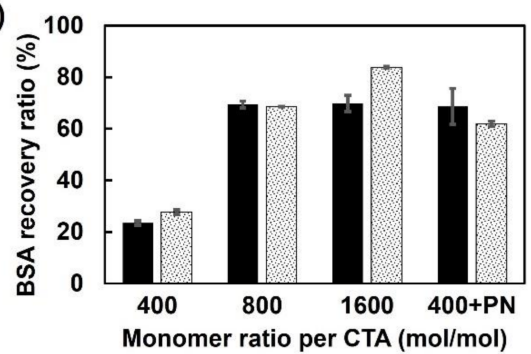

Balance between original solution and supernatant BSA recovery ratio $(\%)=\frac{A-B}{A} \times 100$

(c)

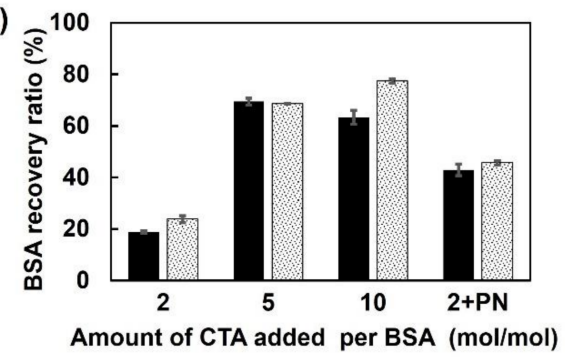

Figure 6. (a) The process of BSA-PNIPAAm conjugates thermal precipitate. (b) Effects of monomer ratio to CTA on BSA recovery ratio (PN: Free PNIPAAm). (c) Effects of CTA ratio to BSA-on BSA recovery ratio (PN: Free PNIPAAm). Calculated from precipitation (black) and a balance between original solution and supernatant (gray). (mean $\pm \mathrm{SD}, n=3$ ).

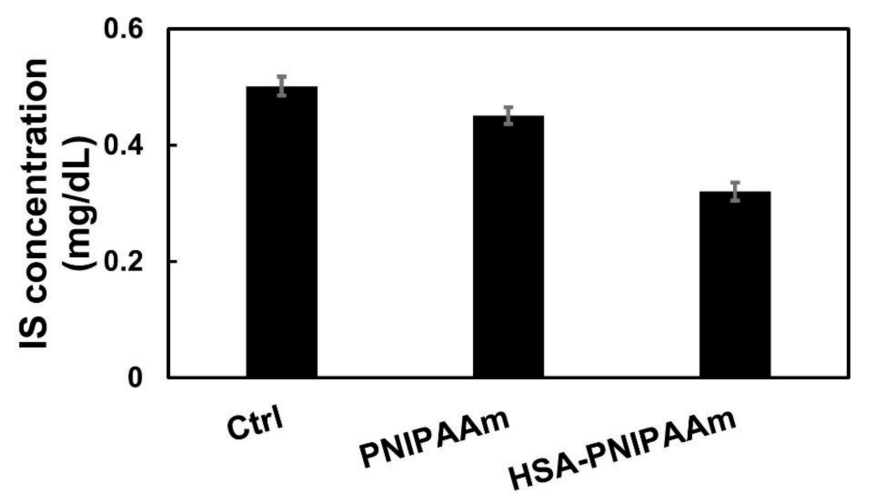

Figure 7. IS concentration in the supernatant after IS adsorption and thermal precipitation using HSA-PNIPAAm conjugate (mean $\pm \mathrm{SD}, n=3$ ).

\section{Materials and Methods}

\subsection{Materials}

N-Isopropylacrylamide (NIPAAm, Fujifilm Wako Pure Chemical (Osaka, Japan), 97\%) was recrystallized from hexane and dried under vacuum before use. 2,2'-Azobis [2-(2imidazolin-2-yl) propane] Dihydrochloride (VA-044, Tokyo Kasei, 98.0\%) was recrystallized 
from methanol and dried under vacuum before use. 2-(Dodecylthiocarbonothioylthio)-2methylpropionic acid $N$-hydroxysuccinimide ester (NHS-CTA, Sigma-Aldrich, St. Louis, MO, USA), N,N-Dimethylformamide (DMF, 99.5\%, Fujifilm Wako Pure Chemical), $0.1 \mathrm{~mol} / 1$ phosphate buffer solution (PB, Nacalai Tesque, Kyoto, Japan), Dulbecco's phosphate-buffered saline (PBS, Sigma-Aldrich), fluorescamine (Tokyo Kasei), Methanol (99.8\%, Fujifilm Wako Pure Chemical), 10×Tris/Glycine/SDS buffer (BIO-RAD), Coomassie brilliant blue R-250 (CBB, BIO-RAD), Laemmli sample buffer (BIO-RAD), 2-Mercaptoethanol (Fujifilm Wako Pure Chemical, 99\%), Precision plus protein unstained standards (BIO-RAD), Bovine serum albumin (BSA, $66 \mathrm{kDa}$, Sigma-Aldrich) Human Serum Albumin (HSA, Nacalai Tesque), Micro BCA $^{\mathrm{TM}}$ Protein Assay Kit (Thermo Fisher Scientific, Waltham, MA, USA), 3-Indoxyl sulfate potassium salt (Carbosynth, Compton, UK), IS assay kits (NIPRO, Osaka, Japan).

\subsection{Synthesis of BSA-CTA}

BSA (66.4 mg, $7 \mu \mathrm{mol})$ and $55 \mathrm{~mL}$ phosphate buffer (PB) (0.1 M, pH 8.0) were added to $100 \mathrm{~mL}$ eggplant flask with a 3-way stopcock and dissolved for $30 \mathrm{~min}$ under argon atmosphere. Next, a mixture of NHS-CTA $(16.3 \mathrm{mg}$, $35 \mu \mathrm{mol})$ dissolved in $3 \mathrm{~mL}$ of DMF was added dropwise to the previous solution and the reaction was continued for $24 \mathrm{~h}$ in a $25^{\circ} \mathrm{C}$ water bath. The reaction mixture was dissolved in $55 \mathrm{~mL}$ of $\mathrm{PB}(0.1 \mathrm{M}, \mathrm{pH} 8.0)$ for $15 \mathrm{~min}$ and the unwanted material was removed by filter paper $(4 \mu \mathrm{m})$ and dialysis (MWCO: 12,000-14,000) in $1 \mathrm{~L}$, three times $(5 \mathrm{~h}, 12 \mathrm{~h}, 24 \mathrm{~h}$ ) with distilled water exchange. The white powder was then recovered by lyophilization.

The amount of CTA group introduced was evaluated by measuring the absorbance intensity of the thiocarbonyl group-derived $310 \mathrm{~nm}$ by UV-vis. Amino residues were also measured by fluorescamine. BSA-CTA $(0.5 \mathrm{mg} / \mathrm{mL}, 50 \mu \mathrm{L})$ and BSA $(0.5 \mathrm{mg} / \mathrm{mL}, 50 \mu \mathrm{L})$ were added to 96 well plates and fluorescamine dissolved in acetone $(50 \mathrm{mg} / \mathrm{mL}, 5 \mu \mathrm{L})$ was added to each well. The fluorescence of each sample was measured using the Infinite M Nano (TECAN, Männedorf, Switzerland) at an excitation wavelength of $395 \mathrm{~nm}$ and a measurement wavelength of $495 \mathrm{~nm}$.

\subsection{BSA-PNIPAAm Conjugates Adjustment Conditions Investigation}

The synthesized BSA-CTA ( $66 \mathrm{mg}, 1 \mu \mathrm{mol})$ and $4 \mathrm{~mL}$ of PB (0.1 M, pH 6.0) were added to a $10 \mathrm{~mL}$ sample tube and dissolved for $30 \mathrm{~min}$. Then, NIPAAm $(452.6 \mathrm{mg}, 4 \mathrm{mmol})$ was added and dissolved in the mixed solution and $1 \mathrm{~mL}$ of PB containing $(50 \mu \mathrm{mol}, 16 \mathrm{mg})$ of initiator VA-044 was added dropwise. Then, the reaction was sealed with argon and carried out in a water bath at $30{ }^{\circ} \mathrm{C}$ for $48 \mathrm{~h}$.

\subsection{BSA-PNIPAAm Conjugates Monomer Ratios and Introduced CTA Groups Investigation}

To investigate monomer ratios, NIPAAm was added in equal amounts of 400 mole, 800 mole and 1600 mole to the CTA groups introduced into BSA. The conjugates were prepared under each condition according to the previous protocol described in (Section 3.2). To investigate the amount of CTA groups introduced into BSA, NHS-CTA was added in equal amounts of 2 mosle, 5 mole and 10 mole against BSA to synthesize BSA-CTA for each condition. Each preparation of the conjugates used the BSA-CTA. BSA-PNIPAAm conjugates properties were evaluated using SDS-PAGE, UV-vis and DLS.

\subsection{SDS-PAGE Measurement}

The succeeded conjugates were characterized by sodium dodecyl sulfate-polyacrylamide gel electrophoresis (SDS-PAGE) compared with BSA and polymer, each one in isolation. The gray scale of SDS-PAGE of each sample was measured by ImageJ (ver. 1.52a, National institutes of health, Bethesda, MD, USA).

\subsection{Lower Critical Solution Temperature Measurement}

The temperature dependence of the transmittance in the prepared samples was measured using a spectrophotometer. The prepared conjugates solution was diluted and 
adjusted to $1 \mathrm{mg} / \mathrm{mL}$ BSA concentration with PBS. The sample solution and the stirring bar were subjected to absorbance measurement using a spectrophotometer in a nitrogen atmosphere at a wavelength of $450 \mathrm{~nm}$, a temperature range of $25^{\circ} \mathrm{C}$ to $40{ }^{\circ} \mathrm{C}$ and a temperature rising rate of $1.0^{\circ} \mathrm{C} / \mathrm{min}$ were applied for measurements [22].

\subsection{DLS Measurement}

The prepared conjugate solution was diluted and adjusted with PBS to the BSA concentration of $1 \mathrm{mg} / \mathrm{mL}$ and measured using a Malvern Zetasizer-Nano ZSP at $\lambda=633 \mathrm{~nm}$, scattering angle $173^{\circ}$ and $35^{\circ} \mathrm{C}$. The diameter and aggregation state of samples were evaluated.

\subsection{BSA Recovery Ratio Evaluation}

The prepared conjugate solution was diluted with PBS to a BSA concentration of $1 \mathrm{mg} / \mathrm{mL}$ and $1 \mathrm{~mL}$ was added to a $2 \mathrm{~mL}$ microcentrifuge tube and centrifuged at $37{ }^{\circ} \mathrm{C}$, $15,000 \mathrm{rpm}$ for $15 \mathrm{~min}$. After aliquoting $900 \mu \mathrm{L}$ of the supernatant, $900 \mu \mathrm{L}$ of PBS was added and the solution was re-dissolved. The BSA concentration of the solution was then measured by the BCA method and the recovery ratio was calculated.

\subsection{The BCA Method}

The prepared conjugate solution was diluted with PBS and adjusted $0.25 \mathrm{mg} / \mathrm{mL}$ BSA concentration. Then, $25 \mu \mathrm{L}$ of this solution and $200 \mu \mathrm{L}$ of working solution (Micro BCA ${ }^{\mathrm{TM}}$ Protein Assay Kit) were added to 96 well plates and incubated at $37^{\circ} \mathrm{C}$ for $30 \mathrm{~min}$. The absorbance of each sample was measured at a wavelength of $562 \mathrm{~nm}$ and the BSA concentration was calculated based on the calibration curve of BSA $(0,0.25,0.5,1.0,2.0 \mathrm{mg} / \mathrm{mL})$.

\subsection{Indoxyl Sulfate (IS) Adsorption Capacity Evaluation}

HSA-PNIPAAm conjugates and IS were dissolved in PBS with $1.0 \mathrm{mg} / \mathrm{mL}$ HSAPNIPAAm constant concentration and IS different concentrations $0-160 \mu \mathrm{g} / \mathrm{mL}$. The solution was shaken at $25^{\circ} \mathrm{C}$ for $2 \mathrm{~h}$ and then centrifuged at $10,000 \mathrm{rpm}$ for $10 \mathrm{~min}$ using a $10 \mathrm{k}$ centrifuge membrane. The IS adsorption capacity of the HSA-PNIPAAm conjugates were prepared and calculated by measuring the IS concentration of the supernatant using the IS measuring reagent "NIPRO" and the adsorption isotherms were plotted out.

For thermal precipitation evaluation, the solution with HSA-PNIPAAm concentration of $2.0 \mathrm{mg} / \mathrm{mL}$ and IS concentration of $5.4 \mu \mathrm{g} / \mathrm{mL}$ was prepared with PBS, followed by shaking at $25^{\circ} \mathrm{C}$ for $2 \mathrm{~h}$. After thermal precipitation by centrifugation at $37^{\circ} \mathrm{C}, 15,000 \mathrm{rpm}$ for $15 \mathrm{~min}$, the IS concentration of the supernatant was measured.

\subsection{GPC and NMR Measurements}

Gel permeation chromatography (GPC) and a spectrophotometer. In ${ }^{1} \mathrm{H} N M R, \mathrm{D}_{2} \mathrm{O}$ was used as a solvent. For GPC (Solvent: THF, Standard: poly (styrene)), the number average molecular weight $(\mathrm{Mn})$, weight average molecular weight (Mw) and molecular weight distribution $(\mathrm{Mw} / \mathrm{Mn})$ of the prepared samples were measured.

\section{Conclusions}

This study successfully synthesized BSA-PNIPAAm conjugates using the GF strategy. The BSA-PNIPAAm conjugates showed different properties by changing the monomer ratio and introducing CTA at low monomer ratios. The high monomer ratio shows high thermal precipitation efficiency. The results indicated that the number of PNIPAAm introduced and a certain amount of chain length affected the thermal precipitation efficiency of the BSA-PNIPAAm conjugates. In addition, HSA-PNIPAAm conjugates showed the ability to adsorb IS, indicating that the activity of albumin was retained during conjugation process. To the best of our knowledge, this research is the first to enhance protein introduction to responsive polymers for uremic toxins purification. The proposed technology is efficient for introducing polymers into proteins, providing wider range of applications in the medical field than traditional methods. In addition, turning albumin into other proteins, such 
as antibodies, can be used for drug delivery systems (DDS) and diagnostic approaches, especially during the current SARS-CoV-2 pandemic situations.

Supplementary Materials: The following supporting information can be downloaded online. Table S1: Feeding ratio of BSA-PNIPAAm for the investigation of monomer concentration; Figure S1: UV-vis measurement results of each BSA-CTA in water $(1 \mathrm{mg} / \mathrm{mL})$; Figure S2: The GPC results of PNIPAAm with and without CTA; Figure S3: Monomer concentration of BSA-PNIPAAm conjugates observed through SDS-PAGE. (Red arrows, no band broadening while yellow arrows show band broadening after conjugation); Figure S4: Gray value of the SDS-PAGE result calculated by image J. (The band on the high molecular weight side with $800 \mathrm{mM}$ was more deep color); Figure S5: ${ }^{1} \mathrm{H}$ NMR spectrum of BSA-PNIPAAm in $\mathrm{D}_{2} \mathrm{O}$; Figure S6: Adsorption isotherm of each sample.

Author Contributions: M.E. designed the research; E.Y., M.S. and A.N. performed the research; E.Y., M.S. and A.N. analyzed data; E.Y. and M.E. designed the figures and wrote the text; E.Y., M.I. and M.E. analyzed and discussed the data. All authors have read and agreed to the published version of the manuscript.

Funding: The research was supported by JSPS KAKENHI Grant-in-Aid for Scientific Research (B) (JP19H04476) and Grant-in-Aid for Transformative Research Areas(A) (JP20H05877).

Institutional Review Board Statement: Not applicable.

Informed Consent Statement: Not applicable.

Data Availability Statement: The data that support the findings of this study are available from the corresponding author, M.E., upon reasonable request.

Acknowledgments: The authors of this manuscript express their great gratitude for Nanotechnology Innovation Station at NIMS for their support. The authors are grateful to Allan S. Hoffman (University of Washington) for continued and valuable discussion.

Conflicts of Interest: The authors declare that they have no conflict of interest.

Sample Availability: Samples of the compounds are not available from the authors.

\section{References}

1. Wright, T.A.; Page, R.C.; Konkolewicz, D. Polymer conjugation of proteins as a synthetic post-translational modification to impact their stability and activity. Polym. Chem. 2019, 10, 434-454. [CrossRef]

2. Cobo, I.; Li, M.; Sumerlin, B.S.; Perrier, S. Smart hybrid materials by conjugation of responsive polymers to biomacromolecules. Nat. Mater. 2015, 14, 143-159. [CrossRef] [PubMed]

3. Heskins, M.; Guillet, J.E. Solution properties of poly(N-isopropylacrylamide). J. Macromol. Sci. Part A-Pure Appl. Chem. 1968, 2, 1441-1455. [CrossRef]

4. Hoffman, J.M.; Ebara, M.; Lai, J.J.; Hoffman, A.S.; Folch, A.; Stayton, P.S. A helical flow, circular microreactor for separating and enriching "smart" polymer-antibody capture reagents. Lab Chip 2010, 10, 3130-3138. [CrossRef] [PubMed]

5. Chen, J.P.; Yang, H.J.; Hoffman, A.S. Polymerprotein conjugates I. Effect of protein conjugation on the cloud point of poly (N-isopropylacrylamide). Biomaterials 1990, 11, 625-630. [CrossRef]

6. Chen, J.P.; Yang, H.J.; Hoffman, A.S. Polymer-protein conjugates II. Affinity precipitation separation of human immunogammaglobulin by a poly( $N$-isopropylacrylamide)-protein A conjugates. Biomaterials 1990, 11, 631-634. [CrossRef]

7. Chen, G.H.; Hoffman, A.S. Synthesis of carboxylated poly (NIPAAm) oligomers and its application to form thermoreversible polymer-enzyme conjugates. Polym. Prepr. 1992, 33, 468-469.

8. Chen, G.H.; Hoffman, A.S. Preparation and properties of thermoreversible, phase-separating enzyme-oligo( $N$-isopropylacrylamide) conjugates. Bioconjug. Chem. 1993, 4, 509-514. [CrossRef]

9. Ding, Z.; Chen, G.; Hoffman, A.S. Synthesis and purification of thermally sensitive oligomer-enzyme conjugates of poly(Nisopropylacrylamide)-trypsin. Bioconjug. Chem. 1996, 7, 121-125. [CrossRef]

10. Takei, Y.G.; Aoki, T.; Sanui, K.; Ogata, N.; Okano, T.; Sakurai, Y. Temperature-responsive bioconjugates. 1. Synthesis of temperature-responsive oligomers with reactive end groups and their coupling to biomolecules. Bioconjug. Chem. 1993, 4, 42-46. [CrossRef]

11. Takei, Y.G.; Matsukata, M.; Aoki, T.; Sanui, K.; Ogata, N.; Kikuchi, A.; Sakurai, Y.; Okano, T. Temperature-responsive bioconjugates. 3. Antibody-poly ( $N$-isopropylacrylamide) conjugates for temperature-modulated precipitations and affinity bioseparation. Bioconjug. Chem. 1994, 5, 577-582. [CrossRef] [PubMed]

12. Chilkoti, A.; Tan, P.H.; Stayton, P.S. Site-directed mutagenesis studies of the high-affinity streptavidin-biotin complex: Contributions of tryptophan residues 79, 108, and 120. Proc. Natl. Acad. Sci. USA 1995, 92, 1754-1758. [CrossRef] 
13. Fong, R.B.; Ding, Z.; Long, C.J.; Hoffman, A.S.; Stayton, P.S. Thermoprecipitation of streptavidin via oligonucleotide-mediated self-assembly with poly( $N$-isopropylacrylamide). Bioconjug. Chem. 1999, 10, 720-725. [CrossRef] [PubMed]

14. Kulkarni, S.; Schilli, C.; Müller, A.H.E.; Hoffman, A.S.; Stayton, P.S. Reversible meso-scale smart polymer-protein particles of controlled sizes. Bioconjug. Chem. 2004, 15, 747-753. [CrossRef]

15. Stayton, P.S.; Shimoboji, T.; Long, C.; Chilkoti, A.; Ghen, G.; Harris, J.M.; Hoffman, A.S. Control of protein-ligand recognition using a stimuli-responsive polymer. Nature 1995, 378, 472-474. [CrossRef] [PubMed]

16. Ding, Z.; Long, C.J.; Hayashi, Y.; Bulmus, E.V.; Hoffman, A.S.; Stayton, P.S. Temperature control of biotin binding and release with a streptavidin-poly ( $\mathrm{N}$-isopropyl acrylamide) site-specific conjugate. Bioconjug. Chem. 1999, 10, 395-400. [CrossRef] [PubMed]

17. Bulmus, V.; Ding, Z.; Long, C.J.; Stayton, P.S.; Hoffman, A.S. Site-specific polymer-streptavidin bioconjugate for pH-controlled binding and triggered release of biotin. Bioconjug. Chem. 2000, 11, 78-83. [CrossRef]

18. Phan, J.C.; Nehilla, B.J.; Srinivasan, S.; Coombs, R.W.; Woodrow, K.A.; Lai, J.J. Human immunodeficiency virus (HIV) separation and enrichment via the combination of antiviral lectin recognition and a thermoresponsive reagent system. Pharm. Res. 2016, 33, 2411-2420. [CrossRef] [PubMed]

19. Boyer, C.; Liu, J.; Bulmus, V.; Davis, T.P.; Barner-Kowollik, C.; Stenzel, M.H. Direct synthesis of well-defined heterotelechelic polymers for bioconjugations. Macromolecules 2008, 41, 5641-5650. [CrossRef]

20. Li, M.; De, P.; Gondi, S.R.; Sumerlin, B.S. Responsive Polymer-Protein Bioconjugates prepared by RAFT polymerization and copper-catalyzed azide-alkyne click chemistry. Macromol. Rapid Commun. 2008, 29, 1172-1176. [CrossRef]

21. Pan, P.; Fujita, M.; Ooi, W.Y.; Sudesh, K.; Takarada, T.; Goto, A. DNA-functionalized thermoresponsive bioconjugates synthesized via ATRP and click chemistry. Polymer 2011, 52, 895-900. [CrossRef]

22. Hironaka, K.; Yoshihara, E.; Nabil, A.; Lai, J.J.; Kikuchi, A.; Ebara, M. Conjugation of antibody with temperature-responsive polymer via in situ click reaction to enable biomarker enrichment for increased diagnostic sensitivity. Biomater. Sci. 2021, 9 , 4870-4879. [CrossRef] [PubMed]

23. Nabil, A.; Yoshihara, E.; Hironaka, K.; Hassan, A.A.; Shiha, G.; Ebara, M. Temperature responsive smart polymer for enabling affinity enrichment of current coronavirus (SARS-CoV-2) to improve its diagnostic sensitivity. Comput. Struct. Biotechnol. J. 2021, 19, 3609-3617. [CrossRef]

24. De, P.; Li, M.; Gondi, S.R.; Sumerlin, B.S. Temperature-regulated activity of responsive polymer-protein conjugates prepared by grafting-from via RAFT polymerization. J. Am. Chem. Soc. 2008, 130, 11288-11289. [CrossRef] [PubMed]

25. Li, H.; Bapat, A.P.; Li, M.; Sumerlin, B.S. Protein conjugation of thermoresponsive amine-reactive polymers prepared by RAFT. Polym. Chem. 2011, 2, 323-327. [CrossRef]

26. Li, H.; Li, M.; Yu, X.; Bapat, A.P.; Sumerlin, B.S. Block copolymer conjugates prepared by sequentially grafting from proteins via RAFT. Polym. Chem. 2011, 2, 1531-1535. [CrossRef]

27. Zhong, W.; Hou, W.; Liu, Y.; Liu, L.; Zhao, H. Biosurfaces fabricated by polymerization-induced surface self-assembly. Langmuir 2020, 36, 12649-12657. [CrossRef]

28. Cai, Y.; Yu, Q.; Zhao, H. Electrostatic assisted fabrication and dissociation of multi-componentproteinosomes. J. Colloid Interface Sci. 2020, 576, 90-98. [CrossRef]

29. Theodorou, A.; Liarou, E.; Haddleton, D.M.; Stavrakaki, I.G.; Skordalidis, P.; Whitfield, R.; Anastasaki, A.; Velonia, K. Proteinpolymer bioconjugates via a versatile oxygen tolerant photoinduced controlled radical polymerization approach. Nat. Commun. 2020, 11, 1486. [CrossRef]

30. Ebara, M.; Hoffman, J.M.; Hoffman, A.S.; Stayton, P.S.; La, J.J. A photo-induced nanoparticle separation in microchannels via pH-sensitive surface traps. Langmuir 2013, 29, 5388-5393. [CrossRef]

31. Ebara, M.; Hoffman, J.M.; Hoffman, A.S.; Stayton, P.S. Switchable surface traps for injectable bead-based chromatography in PDMS microfluidic channels. Lab Chip 2006, 6, 843-848. [CrossRef] [PubMed]

32. Viaene, L.; Annaert, P.; de Loor, H.; Poesen, R.; Evenepoel, P.; Meijers, B. Albumin is the main plasma binding protein for indoxyl sulfate and p-cresyl sulfate. Biopharm. Drug Dispos. 2013, 34, 165-175. [CrossRef]

33. Namekawa, K.; Schreiber, M.T.; Aoyagi, T.; Ebara, M. Fabrication of zeolite-polymer composite nanofibers for removal of uremic toxins from kidney failure patients. Biomater. Sci. 2014, 2, 674-679. [CrossRef]

34. Sasaki, M.; Liu, Y.; Ebara, M. Zeolite composite nanofiber mesh for indoxyl sulfate adsorption toward wearable blood purification devices. Fibers 2021, 9, 37. [CrossRef]

35. Saliba, F. The Molecular Adsorbent Recirculating System $\left(\mathrm{MARS}^{\circledR}\right)$ in the intensive care unit: A rescue therapy for patients with hepatic failure. Crit. Care 2006, 10, 118. [CrossRef] [PubMed]

36. Verbeke, L.; Nevens, F.; Laleman, W. Acute-on-chronic liver failure-Linking the gut, liver and systemic circulation. Crit. Care 2011, 15, 233. [CrossRef] [PubMed] 